\title{
A questão do Eu e do Outro na psicogenética walloniana
}

\author{
The matter of the Self and the Other \\ in Wallon's psychogenetic
}

Laurinda Ramalho de ALMEIDA ${ }^{1}$

\section{Resumo}

Este trabalho examina algumas produções de Henri Wallon, com o propósito de elucidar a relação Eu-Outro. São priorizados dois artigos do autor que tratam especificamente da questão: "O papel do outro na consciência do eu", de 1946 e "Níveis e flutuações do eu", de 1956. Duas questões são postas em discussão: Como se dão as relações EuOutro, a partir da proposição dos estágios de desenvolvimento da teoria de Wallon? Se o Eu se constitui no social, qual o papel do socius na constituição do Eu? Finalmente, a partir das questões discutidas, são apresentadas algumas derivações pedagógicas, com foco no papel do Outro como educador.

Palavras-chave: Comportamento social; Henri Wallon; Relações interpessoais.

\begin{abstract}
This paper examines some of Henri Wallon's works, with the aim of elucidating the relationship between the self and the other. Two of the Wallon's articles, which address this matter specifically, are prioritized: 'The Role of the Other in the Conscience of the Self', from 1946 and 'Levels and Fluctuations of the Self', from 1956. Two matters are discussed: How does the Self-Other relationship occur, based on the proposal of the development stages in Wallon's theory; If the Self constitutes the social, what is the role of the socius in the constitution of the Self? Based on the matters discussed, some pedagogical conclusions are drawn, with a focus on the role of the other as educator.
\end{abstract}

Keywords: Social behavior; Henri Wallon; Interpersonal relationship.

O problema do Outro, afirma Zazzo (1978a), discípulo e colaborador de Wallon, é também o problema do Eu, da condição humana - e não se trata de um problema insolúvel, mas apenas mal colocado. Afirma ainda que Wallon retoma o pro- blema do Outro e, embora não ofereça uma solução perfeita, indica uma direção.

"Wallon não é o único, nem sequer o primeiro a rejeitar a prioridade do Eu como postulado fundamental da Psicologia" (Zazzo, 1978a, p.57).

$\boldsymbol{\nabla v}$

1 Pontifícia Universidade Católica de São Paulo, Faculdade de Educação, Programa de Estudos Pós-Graduados em Educação: Psicologia da Educação. R. Ministro Godói, 969, $4^{\circ}$ andar, Sala 4E-07, Perdizes, 05015-901, São Paulo, SP, Brasil. E-mail: <laurinda@pucsp.br>. 
Com efeito, antes dele, e tomando por referência apenas a tradição da Psicologia americana, William James, J. Marc Baldwin e George H. Mead se esforçaram por apresentar a personalidade como uma construção social. Mas é a Janet (1937), pioneiro da Psicologia francesa, que Wallon recorre para elucidar a noção de socius, porque a convergência de ideias entre os dois teóricos o permitia, embora Janet também tenha se apoiado nas ideias de J. Marc Baldwin. Wallon, que raramente faz referência a outros teóricos em suas obras, cita explicitamente Janet nessa questão (Wallon, 1959/1986a; Zazzo, 1978a).

Zazzo (1978a) aborda a importante contribuição de Wallon para a teorização do problema do Outro, apontando que o autor dedicou apenas dois artigos para o estudo da relação Eu-Outro, publicados com intervalo de dez anos: "O papel do 'outro' na consciência do 'eu'" e "Níveis e flutuações do eu". O primeiro foi publicado em 1946 no "Journal Egyptien de Psychologie", e o segundo, em "L'évolution Psychiatrique", em 1956; ambos reproduzidos em números especiais da revista "Enfance", em 1973, os quais foram editados em Portugal, respectivamente como "Psicologia e Educação da Infância" (1975) e "Objectivos e Métodos da Psicologia" (1975).

Registra ainda Zazzo (1978a) que na obra de Wallon aparecem três concepções de Outro:

- os outros das relações interpessoais;

- o outro como conceito geral, para todos com os quais o indivíduo se relaciona;

- o socius ou outro íntimo.

O propósito deste artigo é retomar alguns textos de Wallon, em especial os dois referidos, tentando elucidar as seguintes questões:

- Como as relações Eu-Outro se apresentam nos diferentes estágios de desenvolvimento da teoria walloniana?

- Se a pessoa se constitui no social, qual o papel do socius na constituição do Eu?

\section{Da socialização para a individuação}

Em "O papel do Outro na consciência do $E u^{\prime \prime}$, Wallon exprime um pensamento que é reiteradamente citado por seus estudiosos: "o indivíduo, se ele se apreende como tal, é essencialmente social. Ele o é, não em virtude de contingências externas, mas devido a uma necessidade íntima. Ele o é geneticamente" (Wallon, 1959/1986a, p.164). Ou seja, a natureza social do homem não é acrescentada por circunstâncias externas, mas o social já está inserido no biológico, como uma necessidade, pois, sem o social, não se faz homem.

O recém-nascido necessita do Outro não só para a sobrevivência física, não só por sua condição de fragilidade quando comparado a outras espécies, mas também para sua sobrevivência cultural, para agir de acordo com os padrões do grupo ao qual pertence ou pertencerá. É a resposta do Outro, ao discriminar e atender às necessidades do recém-nascido, que vai imprimir nele os moldes culturais. Para expressar suas necessidades e ser atendido pelo Outro do seu entorno, os recursos de que dispõe inicialmente são o grito, o choro e os movimentos descoordenados provocados pelas sensibilidades interoceptivas (das vísceras) e proprioceptivas (dos músculos) $)^{2}$. Desse modo, dá-se a fusão com os que Ihe são próximos e, embora se tratando (bem no início da vida) de simples automatismos, estes, segundo Wallon, já lembram o caráter contagioso das emoções. É então, pela emoção, essencialmente orgânica, visível, expressa pelos movimentos, ao ser garantida a aproximação do Outro, que o recém-nascido tem sua primeira ligação com a cultura. É pela emoção também que o recém-nascido tem sua primeira forma de ação sobre o Outro. Pela emoção, o indivíduo, antes de pertencer a si próprio, pertence ao seu meio.

O processo de desenvolvimento psíquico do indivíduo caminha, portanto, da socialização para uma diferenciação gradual, que torna cada indivíduo um ser único e diferente dos demais. Essa rela-

\footnotetext{
$\nabla \nabla \nabla \nabla$

2 Sensibilidades interoceptivas, proprioceptivas e exteroceptivas (provocadas por estímulos externos) são termos cunhados por Sherrington, 
ção indivíduo-meio social é recíproca: o meio social transforma o indivíduo, e este transforma o meio social por suas reações.

A relação Eu-Outro permeia todo o processo de desenvolvimento, de forma sincrética, no período inicial da vida psíquica, caminhando para uma progressiva diferenciação. A consciência de si, que implica a diferenciação Eu-Outro, vai ocorrer mais tarde. Essa transversalidade da questão Eu-Outro na obra walloniana leva Zazzo (1978a, p.64) a afirmar: "se a teoria do Outro vem na sua obra depois da teoria da emoção, da qual é como que a consequência e o desenvolvimento, esta fornece àquela os seus materiais, os seus argumentos mais decisivos".

Enfatizar a relação Eu-Outro não significa negar a importância do meio físico para a evolução das espécies, mas, sim, afirmar que a característica da espécie humana é o fato de ter sobreposto ao meio físico o meio social, espaço no qual estão em constante complementação/oposição o Eu e os Outros. O indivíduo pensa, sente e age de acordo com os padrões culturais de seu grupo; a vida intelectual supõe a vida social; é o meio social que oferece as balizas para a expressão de emoções, sentimentos e paixão, que englobam a dimensão afetiva; é, enfim, o meio que impõe possibilidades/limites ao desenvolvimento cognitivo-afetivo-motor do indivíduo.

Todas as análises wallonianas mostram a relação complementar e recíproca entre os fatores orgânicos e socioculturais, o que é coerente com os pressupostos do materialismo dialético que sustenta os estudos do autor: "a integração genético-social é o resultado da oposição que obriga aquilo que existe a se modificar para continuar a existir" (Wallon, 1990, p.129).

\section{O sistema de estágios na teoria de desenvolvimento de Henri Wallon}

Da unidade organismo-meio, postulada pela psicogenética walloniana, resultam os conjuntos funcionais - motor, afetivo, cognitivo, pessoa -, que formam o psiquismo humano. Estes funcionam de forma integrada, ou seja, uma estimulação em um deles reflete sobre os demais, e com predominância de um ou outro em função do orgânico e do social: o orgânico entendido como campo das possibilidades dadas pelas condições neurológicas, e o social, como campo de condições para concretizar ou não as possibilidades, conforme as solicitações e recursos do meio.

O conjunto motor oferece as formas de deslocamento: 1. deslocamentos do corpo no tempo e no espaço, em função das leis da gravidade; 2 . movimentos voluntários ou intencionais do corpo ou partes dele; 3. reações posturais que se caracterizam por mímicas e expressões faciais, diante das diferentes situações.

O conjunto cognitivo oferece as possibilidades para a aquisição, manutenção e transformação do conhecimento. Permite rever e reelaborar o passado, fixar e analisar o presente e projetar o futuro.

O conjunto afetivo engloba emoções que, por serem expressões corporais, visíveis, ativadas pelo fisiológico, são a expressão da afetividade; os sentimentos correspondem à expressão representacional da emoção, não implicam reações diretas e instantâneas como na emoção, e tendem a limitar sua potência; a paixão corresponde ao controle da emoção pelo intelecto em função de objetivos muito claros.

Pessoa, o quarto conjunto funcional, garante a integração cognitivo-afetivo-motora e é o resultado dessa integração.

A "abordagem genética, concreta e multidimensional" (Tran-Thong, 1983, p.15) utilizada por Wallon para seus estudos psicogenéticos, que implica considerar a criança no conjunto total de suas atividades e de seus comportamentos, bem como no conjunto das suas condições de existência, permitiu-lhe examinar as constâncias ao longo do desenvolvimento - um desenvolvimento que não é linear, mas oscilatório. Dessa forma, identificou seis estágios que se diferenciam por suas características, de modo que em cada estágio predomina um ou outro conjunto funcional. 
Estas revoluções de idade para idade não são improvisadas por cada indivíduo. São a razão da infância, que tende à realização do adulto como exemplar da espécie. Estão inscritas, em seu momento, no desenvolvimento que deve levar a isso. As incitações do meio são sem dúvida indispensáveis para que se manifestem e, quanto mais elevado o nível da função, mais ela sofre a determinação dele... (Wallon, 1941/2007, p.192)

Os estágios propostos são os seguintes:

- impulsivo (do nascimento aos 3 meses) e emocional (dos 3 meses a 1 ano);

- sensório-motor e projetivo (dos 12 meses aos 3 anos);

- personalismo (dos 3 aos 6 anos);

- categorial (dos 6 aos 11 anos);

- puberdade e adolescência (acima dos 11 anos);

- adulto.

Vale lembrar que as idades indicadas o foram em função do contexto histórico-cultural da época. Mais importante que limites de idade, são os interesses e atividades que aparecem em cada estágio. Importante lembrar também que cada estágio prepara o seguinte, de sorte que algumas características de um estágio já podem aparecer no estágio que o precede.

São três as leis de desenvolvimento reguladoras da sequência dos estágios:

- lei da alternância funcional: é a "lei da alternância entre as fases orientadas para a realidade das coisas ou para a edificação da pessoa" (Wallon, 1975a, p.69). Trata-se da alternância de direções opostas entre estágios: o movimento se dá ora para fora, para o conhecimento do mundo exterior (direção centrífuga, catabólica, de dispêndio de energia), ora para dentro, para o conhecimento de si (direção centrípeta, anabólica, de acúmulo de energia);

- lei da predominância funcional: alternância do predomínio de um ou outro conjunto funcional a cada estágio, embora os conjuntos funcionais se nutram mutuamente, pois o amadurecimento de

598 um interfere nos outros;
- lei da integração funcional: a relação entre os estágios é uma relação hierarquizada entre os conjuntos funcionais; os primeiros estágios são conjuntos mais simples, com atividades mais primitivas, que vão sendo integradas às atividades mais complexas dos estágios seguintes.

Conforme essas leis, os seis estágios de desenvolvimento apresentam características distintas quanto ao conjunto e à direção:

- no estágio impulsivo-emocional, predominam os conjuntos motor e afetivo, e a direção é centrípeta, (direção para dentro, para o conhecimento de si, com acumulo de energia);

- no sensório-motor, predomina o conjunto cognitivo, e a direção é centrífuga, (direção para fora, para o conhecimento de mundo exterior, com dispêndio de energia);

- no personalismo, predomina o conjunto afetivo, e a direção é centrípeta;

- no categorial, predomina o conjunto cognitivo, e a direção é centrífuga;

- na puberdade e adolescência, predomina o conjunto afetivo, e a direção é centrípeta;

- no adulto, há um equilíbrio afetivo e cognitivo.

É importante observar que o conjunto motor só apareceu no estágio impulsivo-emocional porque a linguagem emocional - que traduz as emoções e leva o outro a responder a elas, característica desse estágio -, tem no movimento seu recurso de visibilidade. No entanto, a integração afetivo-cognitivo-motora se faz presente em todo o transcorrer do desenvolvimento.

Este trabalho procura focalizar as relações Eu-Outro em cada um dos estágios de desenvolvimento, ou seja, analisa o tipo característico de relação que o indivíduo mantém com o Outro do seu entorno social, em cada um dos estágios.

Inicialmente, no estágio impulsivo-emocional, as relações são predominantemente simbióticas. Trata-se de uma simbiose afetiva, porque a sensibilidade da criança parece alimentar-se, por osmose, da estimulação do meio social. É um período de fusão Eu-Outro. No recém-nascido, as 
gesticulações esporádicas e descontínuas não têm nenhuma utilidade, nem sequer para modificar uma posição incômoda. Precisa da assistência constante do Outro para satisfazer suas necessidades. "Incapaz de efetuar algo por si próprio, ele é manipulado pelo Outro e é, nos movimentos desse Outro, que suas primeiras atitudes tomarão forma" (Wallon, 1986a, p.161).

Se os gestos não lhe são úteis, por outro lado, vão suscitar nos Outros do seu entorno intervenções úteis para satisfazer suas necessidades. Logo a criança passa a perceber os sinais que indicam sucesso ou frustração para o atendimento de suas necessidades. E o gesto deixa de ser puro ato motor e começa a ter uma intenção, a ser expressão de emoções que começam a se diferenciar. Nesse início de psiquismo, não são feitas delimitações Eu-Outro. A união do sujeito com o ambiente é indiscernível:

O período inicial do psiquismo parece, pois, ter sido, contrariamente à concepção tradicional, um estado de indivisão entre o que depende da situação exterior ou do próprio sujeito. Tudo o que acede simultaneamente à consciência aí permanece confundido, ou, pelo menos, as delimitações que aí podem ser feitas não são, de início, aquelas entre o eu e o outro, entre o ato pessoal e seu objetivo exterior. A união da situação ou do ambiente com o sujeito começa por ser global e indiscernível (Wallon, 1986a, p.162).

As reações impulsivo-motoras dos primeiros meses se tornam cada vez mais expressivas; por volta dos três meses, o bebê já se dirige aos que cuidam dele com movimentos, sorrisos e olhares de contentamento, e chora quando alguém que se ocupa dele se afasta. É esse diálogo sem palavras, elo predominantemente afetivo, o começo da comunicação humana. A resposta pelo sorriso ao Outro constitui um indicador do início de uma atividade de relação, mas não significa ainda a distinção Eu-Outro. Quando a criança chora pelo afastamento do Outro "parece que esta partida a descompleta, como se ela formasse uma unidade com o seu ambiente" (Wallon, 1956/1975b, p.155).
Já no estágio sensório-motor, o sincretismo e a simbiose afetiva se relaxam. É o período das relações de reciprocidade bipolar ou de alternância de papéis. Desde o sétimo ou oitavo mês já se observam entre as crianças situações com papéis contrastados ou complementares (que se explicam pelo binômio contemplação-exibição), mas é no decorrer do segundo ano de vida que as relações recíprocas estão mais evoluídas: "a simbiose afetiva que mantém o seu Eu como que dissolvido nas suas relações com os outros sofre em breve duma contradição que não pára de crescer no decorrer do segundo ano" (Wallon, 1956/1975b, p.156).

Os jogos de alternância, nos quais a criança ora é autora em relação ao Outro, ora é objeto do Outro (dar e receber um tapa, por exemplo), são trocas de papel com o Outro, que levam a criança a conhecer o desdobramento entre o que age e o que sofre a ação. Mas isso ainda não significa a afirmação de um ponto de vista pessoal: "O Eu não assumiu, ainda, diante do Outro, esta espécie de estabilidade e constância que nos parece indispensável à consciência de si, que parece ser constitutiva da pessoa" (Wallon, 1986a, p.162).

Isso não impede que se observem nas crianças atividades de relação Eu-Outro. Esse aspecto é bem abordado por Wallon no que denomina sensibilidade à presença ou reação de prestance.

Em "As origens do caráter na criança", obra editada pela primeira vez em 1949, Wallon descreve minuciosamente a sensibilidade à presença (prestance), muito primitiva na criança (que persiste em todo o processo de desenvolvimento) e que corresponde ao despertar de atitudes ligadas à aproximação ou à presença do Outro. Ainda toscas e não diferenciadas, tais atitudes já começavam a aparecer no período impulsivo-emocional. No sensório-motor, ocorre um tipo particular de relação entre o sujeito e seu ambiente. O efeito mais habitualmente verificado é "uma influência dinamogênica, excitante, sobre a atividade da criança. Ela solicita frequentemente a ação de alguém quando julga estar realizando algo difícil. Toma melhor sua sopa quando supõe que um amiguinho imaginário está olhando" (Wallon, 1949/1995, p.270). 
Depois dos três anos, essa atenção tende a se diversificar e se relacionar com as circunstâncias e as pessoas. É quando surge a vergonha.

Durante todo o processo de desenvolvimento, em todos os estágios, atitudes ligadas à aproximação ou presença do Outro ocorrem:

Sob a insistência de um olhar, sob a impressão de ser para o outro um objeto de atenção, pode ocorrer a todo mundo de sentir-se embaraçado. Trata-se de um desarranjo que atinge o sistema de atitudes. ... Mais frequentemente, os gestos, o andar, a própria postura tornam-se menos seguros. 0 sujeito torna-se bruscamente desajeitado, deixa cair o que traz, duvida de seu equilíbrio, põe-se a tremer. Mostra, assim, sinais evidentes de assinergia ... (Wallon, 1949/1995, p.121).

Outra bela descrição das relações criança-criança é feita na mesma obra "As origens do caráter na criança", referindo-se ao ciúme e à simpatia: "O estado de fusão com o Outro, expresso por uma situação afetiva, explica manifestações aparentemente muito complexas, porém de aparecimento precoce, tais como o ciúme e a simpatia" (Wallon, 1949/1995, p.240). Wallon identifica as primeiras manifestações de ciúme a partir dos nove meses, argumentando que este adquire formas e motivos correspondentes aos progressos da idade. Quanto às manifestações de simpatia afirma que:

... é vasto o campo de manifestação de simpatia. No entanto, é preciso, ao mesmo tempo, distingui-la do mimetismo afetivo do qual ela procede... . A simpatia pode se manifestar a princípio em dois sentidos contrários: centrífugo e centrípeto. No primeiro caso, a criança transfere o objeto habitual de seus próprios desejos ou de seus temores

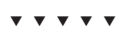

3 O tradutor (Wallon, 1956/1975) esclarece que Je e Moi podem significar Eu. No entanto, Je (eu sujeito) refere-se ao termo que a criança usa para designar-se a si própria; Moi (eu complemento) refere-se a uma relação da criança com o mundo exterior. Os autores deste estudo acrescentam que, antes dos 3 anos, a criança distingue-se mal das situações pelas quais passa. ela reage àquilo que interessa ou ameaça a outra, como se tratasse dela própria. Com cerca de um ano... (Wallon, 1949/1995, p.244).

A seguir, no estágio do personalismo, por volta dos três anos, eclode uma crise de personalidade que atesta a afirmação do Eu como diferente do Outro, por meio das relações de oposição (expulsão do Outro), de sedução (assimilação do Outro) e de imitação (o Outro como modelo). Tais movimentos correspondem às três etapas do personalismo: crise de oposição (três a quatro anos), idade da graça (quatro a cinco anos) e imitação (cinco a seis anos). Acentua-se o processo de discriminação entre o Eu e o Outro; separa-se o Eu do Outro, o que se revela no uso insistente da primeira pessoa: Meu, Eu, Não quero. "A elaboração do Eu e do Outro por parte da consciência faz-se simultaneamente. São dois termos conexos cujas variações são complementares e as diferenciações recíprocas" (Wallon, 1956/1975, p.159). A distinção, agora nítida, entre o Eu e o Outro inicia um diálogo em igualdade de condições, ambos como sujeitos da relação.

Em todas as coisas pretende afirmar uma
posição pessoal, nem que seja para contra-
dizer a posição assumida por outros. É afinal
a época em que, deixando de designar-se
na terceira pessoa emprega, por vezes com
ostentação, os pronomes Eu sujeito e Eu
complemento ${ }^{3}$. Por extensão do seu senti-
mento pessoal aos objetos, o Meu ganha
um significado bem preciso de posse: existe
o objeto emprestado, cuja utilização é ape-
nas momentânea, e aquele que pertence
permanentemente à mesma pessoa. Desde
os 3 anos que a criança é capaz de fazer es-
ta distinção a seu favor (Wallon, 1956/1975,
p.158).

A seguir, no estágio categorial, as relações Eu-Outro são de reciprocidade mais igualitária. A diferenciação nítida entre o Eu e o Outro dá con- 
dições estáveis à criança para exploração mental do meio físico, e a organização desse meio em categorias mais bem definidas possibilita também uma compreensão mais nítida de si mesma. A criança percebe-se separada do Outro, com possibilidade de inserir-se em diferentes grupos e ser classificada neles conforme as atividades propostas. Nos grupos, estabelecem-se relações de cooperação (igualdade) ou de exclusão (rivalidade).

Posteriormente, no estágio de puberdade e adolescência, surge outra vez a exploração de si mesmo, como acontece no personalismo, porém com maior autonomia. As relações Eu-Outro são de conflito e oposição: relações de confronto aos valores tais como interpretados pelos adultos com os quais convive e, ao mesmo tempo, relações de submissão ao grupo de pares. Pelo desejo de chamar a atenção, para autoafirmação, as relações podem ser de arrogância.

Por fim, no adulto, com o controle cortical sobre as situações, as relações Eu-Outro tendem a ser mais igualitárias.

\section{Os Outros, o Outro, o Outro Íntimo ou Socius, o Eu}

A partir de estudos e pesquisas, no confronto com o real, Wallon elaborou sua teoria de desenvolvimento. De forma cristalina, mostrou que o psiquismo é o fato novo que, na espécie humana, surge da integração entre o organismo e o social; que a relação Eu-Outro permeia toda a constituição psíquica do indivíduo, desde quando recém-nascido (de forma sincrética, nebulosa) até a morte; que, conforme o indivíduo vai se reconhecendo como eu, também vai reconhecendo o Outro, pois a elaboração do Eu e do Outro para a consciência faz-se simultaneamente.

Conforme já apontado, Zazzo (1978a) identifica na obra de Wallon três tipos de Outro: os Outros referem-se àqueles com os quais o indivíduo interage concretamente, nas relações interpessoais; o Outro é referido como conceito geral, que engloba todos os Outros em sua pluralidade; o Outro íntimo ou socius é o parceiro constante, permanente do Eu na vida psíquica.

\section{A Psicologia interpessoal de Wallon}

Trevarthen (1993), professor da Universidade de Edinburgh, Escócia, no evento comemorativo aos 30 anos da morte de Wallon, proferiu uma alocução com o título "Uma apreciação da psicologia interpessoal de Henri Wallon", apontando o quanto os trabalhos do autor o impressionaram, pela importância dada ao afetivo e por Ihe terem evidenciado que a aprendizagem humana é colorida por sentimentos transmitidos no diálogo, nos jogos, nas tarefas cooperativas, e sempre influenciada por atitudes de respeito, admiração e orgulho: "A Psicologia de Wallon entendeu esse aspecto interpessoal, e nós ainda podemos apreciá-lo melhor com seus olhos" (Trevarthen, 1993, p.45).

Segundo Trevarthen, com os modernos métodos para gravar e microanalisar os comportamentos, poder-se-ia "expandir a visão profética de Wallon" quanto às formas de relacionamento e expressão entre crianças e entre adultos-crianças. Em especial, referia-se à descrição de prestance elaborada por Wallon. O fato de uma criança, aos seis meses já ter uma clara sensibilidade de que é o centro de curiosidade e admiração do Outro; de uma criança pequena, ao sentir a presença de Outros, exibir-se, mostrar-se orgulhosa, ou sentir-se intimidada, culpada ou ciumenta; são questões que, segundo Trevarthen, por sua importância, merecem ser pesquisadas.

\section{O Eu e o socius}

Ao se discutirem as relações Eu-Outro nos vários estágios de desenvolvimento, salienta-se que, no período inicial do psiquismo, a união da situação ou do ambiente com o sujeito é global e indiscernível - Eu e Outro são indivisos.

Wallon usa de uma metáfora para explicar esse período e sua sequência:

Poder-se-ia comparar o primeiro estado da consciência a uma nebulosa, onde ações sensitivo-motoras de origem exógena ou endógena se difundiriam sem delimitação própria. Em sua massa acabariam por se formar um núcleo de condensação, o eu, mas 
também um satélite, o sub-eu, ou o outro (Wallon, 1986a, p.164).

Entre os dois - Eu e Outro, a repartição da matéria psíquica não é necessariamente constante, lembra Wallon. Varia conforme a idade, o indivíduo e as circunstâncias; em situações de crise tais que levem à obnubilação mental, o que era atribuído ao Outro pode ser novamente reabsorvido pelo Eu, ou a preponderância pode passar do Eu ao Outro, ou até as fronteiras entre o Eu e o Outro podem desaparecer.

A partir do momento em que o Eu se afirma, quando claramente se faz a sua delimitação em relação ao Outro, há apenas um personagem, mas o segundo não desaparece totalmente. É daí que surge o Outro íntimo, ou socius, termo utilizado por Pierre Janet e assumido por Wallon, que também se refere a ele como alter.

Trata-se do socius de Pierre Janet; um duplo do Eu que lhe é concomitante e consubstancial, mas que nem sempre condiz com ele, tão longe dele está. Ele é o suporte da discussão interior, da objeção às determinações ainda duvidosas [...]. O Alter não é qualquer outro, há também os outros: Alii. Mas segundo termo dum par insolúvel, companheiro permanente do Eu, o Alter possui o papel de intermediário ou de charneira entre o mundo interior e o mundo concreto do ambiente (Wallon, 1956/1975, p.164).

Portanto, o socius, que surge a partir da diferenciação Eu-Outro, tem em sua constituição elementos oriundos das relações com diferentes tipos de meio. Por outro lado, as ações do indivíduo com seu meio real, concreto, são mediadas pelo alter ou socius: "mas esta relação [entre o indivíduo e o meio real] parece ter por intermediário o fantasma do outro que cada um traz consigo" (Wallon, 1986a, p.164). socius é normalmente inaparente, como que negado pela vontade de dominação e de integridade do Eu, mas ganha força e expressão em momentos de insegurança, de dificuldade, de tomada de de-

602 cisão. Nesses momentos, a força do socius pode se manifestar na forma de um diálogo íntimo ou expresso: "... há pessoas que se questionam e que respondem a si próprias com uma animação ou mesmo uma agressividade crescente" (Wallon, 1986a, p.165), ora reduzindo o socius a uma submissão a si, ora se submetendo a ele.

A noção de socius, afirma Zazzo (1978b) só tardiamente aparecerá de forma explícita na obra de Wallon. Se considerada isoladamente, não é sua contribuição mais pessoal, mas "Wallon integra-a com uma felicidade de expressão e uma força que a torna como que o remate de sua obra, a última peça que confere ao conjunto amplitude significante" (Zazzo, 1978b, p.47).

Na homenagem prestada a "Pierre Janet, psicólogo realista", Wallon esclarece:

É desse desdobramento da pessoa que mais tarde Janet deveria tirar, sob o nome de socius um fantasma normal e permanente: essa testemunha, esse interlocutor, esse juiz, esse contraditor que acompanha passo a passo nossos planos, nossas deliberações mais íntimas, que é o complemento indispensável de nossa pessoa (Wallon, 1968a, p.143-144).

Este texto de homenagem a Janet esclarece tanto o conceito de socius como de Eu. Refere-se a socius como complemento indispensável da pessoa (personne no original francês) e não Eu. É a mesma palavra que usa para se referir aos conjuntos ou domínios funcionais: "Les domaines fonctionnels ... seront ceux de l'affectivité, de l'acte moteur, de la connaissance et de la personne" (Wallon, 1968b, p.119).

O Eu da psicogenética walloniana refere-se ao quarto conjunto funcional - pessoa -, o qual, ao mesmo tempo que garante a integração entre os conjuntos afetivo, motor e cognitivo, é o resultado dessa integração. Esse raciocínio é corroborado pela afirmação de Wallon de que Janet passa o Eu do plano metafísico para o plano psicogenético.

Um ponto pode ainda ser enfatizado para a resposta à segunda questão proposta a discussão neste artigo: Se o indivíduo se constitui no social, qual o papel do socius na constituição do Eu? 
Também o texto-homenagem a Janet apresentou a pessoa não como um ser com atitudes ditadas pelo que se espera dele, mas sob uma forma dinâmica, numa hierarquia de atividades que vão desde as mais automáticas até as mais refletidas; apresentou-a como autora de seu próprio destino.

Essa autoria se faz na medida em que se esforça para se individualizar e "em seu esforço para se individualizar, o eu não pode fazer outra coisa a não ser opor-se à sociedade sob a forma primitiva e larval de um socius, conforme a expressão de Pierre Janet" (Wallon, 1986a, p.164).

É, pois, o diálogo Eu-Socius que, no processo de desenvolvimento, facilita a individuação e promove o dinamismo e o enriquecimento do Eu.

Wallon (1956/1975) faz uma bela análise da relação Eu-Socius a partir da literatura, enfocando a transfiguração do Eu e sua posterior reintegração. Toma D. Quixote para fazê-la. Feio, levando uma existência monótona, começa por despojar-se de seu Eu lendo romances de cavalaria, realizando as proezas de seus heróis. A seguir, para negar completamente a si próprio e a seu ambiente, transforma moinhos de vento em combatentes. É com enorme esforço que reduz seu Eu real a uma simples aparência para se identificar ao socius que tinha formado. Mas o seu Eu o persegue: toma consciência disso quando é repelido pelos que não querem aceitar suas metamorfoses. Quando chega a hora da morte, que enfrenta com humanidade e nobreza, é a seu Eu que é resignado a se reintegrar.

Se D. Quixote parece por vezes aproximar-se da alienação, é uma alienação voluntária e quase consciente. Ele alienou-se num Eu fictício no qual condensou, em oposição a sua fraca pessoa, a generosidade e grandeza que nele não podiam encarnar-se. Trata-se aqui da substituição do Ego pelo Alter. Assim, o Eu e seu complemento inseparável, o Outro, conduzem a pessoa duma sensibilidade elementar aos horizontes mais diversos e por vezes mais vastos da consciência individual ou coletiva (Wallon, 1956/1975, p.171).

O Eu dialoga com o socius e, nesse diálogo, num dinamismo e devir constantes, um ou outro sai vencedor, dependendo das circunstâncias. A singularidade do indivíduo se realiza na dialética do Eu e do Outro.

\section{Algumas derivações pedagógicas}

A teoria walloniana postula que o meio é um complemento indispensável ao ser vivo e que os indivíduos podem pertencer a meios sociais variados.

Vários meios podem, então, superpor-se pa-
ra um mesmo indivíduo e até entrar em con-
flito. Alguns são vergonhosos, outros vanta-
josos, alguns são renegados e outros deseja-
dos. Assim a existência dos meios reais pode
ser duplicada, para a criança, por julgamen-
tos de valor ou por aspirações imaginativas,
no decorrer das quais ela opõe a situação
que desejaria para si e a situação do outro
ao seu próprio destino. Os meios em que
vive e aqueles com os quais sonha são a
fôrma que deixa nela sua marca. Não se trata
de uma marca recebida passivamente. Com
certeza, os meios dos quais a criança depen-
de começam por comandar muitas de suas
condutas, e o hábito precede à escolha. Mas
a escolha pode se impor, seja para resolver
desacordos, seja para comparar seus pró-
prios meios a outros (Wallon, 1959/1986b,
p.171).

A escola é um desses meios - meio funcional, porque tem uma função outorgada pela sociedade: fazer chegar à criança, ao jovem e ao adulto o acervo cultural que a humanidade já construiu, bem como contribuir para sua conservação e expansão. As crianças a frequentam, argumenta Wallon, para se instruírem e se familiarizarem com um novo tipo de disciplina e de relações interindividuais.

Ao aceitar que os profissionais da educação devem agir proveitosamente sobre o meio escolar para torná-lo mais propício ao desenvolvimento de crianças, jovens e adultos que o frequentam, compete pensar:

- Que Outro pode ser o educador para potencializar o desenvolvimento de seu aluno? 
- Como ser, para o aluno, um Outro que contribua com elementos para a constituição de um Eu mais forte, menos fragilizado neste período no qual a sociedade passa por tão profundas e rápidas transformações?

A discussão teórica apresentada aponta para algumas possibilidades:

- reconhecendo que os Outros têm um papel essencial no processo de desenvolvimento, e que, queira-se ou não, os educadores são Outros importantes para o aluno;

- reconhecendo que os educadores, Outros, principalmente ao tratarem com a criança pequena, são portadores da cultura, na medida em que lhe dão a significação para objetos e pessoas;

- aceitando que é fundamental o conhecimento do aluno, de suas condições de existência, de suas características, das relações que ele estabelece nos diferentes meios, não para etiquetá-lo ou classificá-lo, mas para promover seu desenvolvimento;

- sendo um Outro que favoreça a constituição de um meio escolar que ofereça condições para o exercício das competências correspondentes a cada estágio de desenvolvimento;

- sendo um Outro que evidencie, por ideias e por ações, que a educação tem um papel transformador para o indivíduo e para a sociedade;

- sendo um Outro que não poupe esforços para uma constante qualificação, exigindo das devidas instâncias uma formação adequada e contínua.

A questão do Eu e do Outro, posta por Wallon já na primeira metade do século passado, continua sendo de extrema pertinência na sociedade de hoje, cujas rápidas transformações exigem que se repense continuamente a relação Eu-Outro. Os educadores são o Outro do Outro que procura a escola; seu compromisso é com uma prática pedagógica que tenha por objetivo o fortalecimento da pessoa - uma pessoa com conhecimento de si e do mundo, que possa expressar emoções e sentimentos, que tenha respeito por si mesma e pelo
Outro e que, assim fortalecida, seja solidária em suas relações Eu-Outro.

\section{Referências}

Janet, P. (1937). Les condutes sociales. In Actes du Onzième Congrès International de Psychologie, Paris.

Trant-Thong (1983). Estádios e conceito de estádio de desenvolvimento da criança na psicologia contemporânea (Vol. 2). Porto: Afrontamento.

Trevarthen, C. (1993). An appreciation of the interpersonal psychology of Henri Wallon. Enfance, 47(1), 41-46.

Wallon, H. (1968a). Pierre Janet, psychologue réaliste. Enfance, 21(1-2), 143-145.

Wallon, H. (1968b). L'evolution psychologique de I'enfant. Paris: Armand Colin.

Wallon, H. (1975a). A psicologia genética. In H. Wallon. Psicologia e educação da infância (pp.53-72). Lisboa: Estampa.

Wallon, H. (1975b). Níveis e flutuações do eu. In H. Wallon. Objectivos e métodos de psicologia (pp.153-171). Lisboa: Estampa. (Originalmente publicado em 1956).

Wallon, H. (1986a). O papel do outro na consciência do Eu. In M. J. Werebe, \& J. Nadel-Brulfert (Orgs.), Henri Wallon (pp.158-167). São Paulo: Ática. (Originalmente publicado em 1959).

Wallon, H. (1986b). Os meios, os grupos e a psicogênese da criança. In M. J. Werebe, \& J. Nadel-Brulfert (Orgs.), Henri Wallon (pp.168-178). São Paulo: Ática. (Originalmente publicado em 1959).

Wallon, H. (1990). Matérialisme dialectique et psychologie. In E. Jalley, \& L. Maury. Henri Wallon: psychologie et dialectique écrits de 1926 à 1961 (pp.128-139). Paris: Messidor.

Wallon, H. (1995). As origens do caráter na criança. São Paulo: Nova Alexandria. (Originalmente publicado em 1949).

Wallon, H. (2007). A evolução psicológica da criança. São Paulo: Martins Fontes. (Originalmente publicado em 1941).

Zazzo, R. (1978a). O problema do Outro na psicologia de Henri Wallon. In R. Zazzo. Psicologia e marxismo (pp.55-66). Lisboa: Vega.

Zazzo, R. (1978b). Do corpo à alma. In R. Zazzo. Psicologia e marxismo (pp.35-81). Lisboa: Vega.

Recebido em: 29/8/2012

Versão final em: 1/7/2013

Aprovado em: 6/9/2013 